\title{
Sickle Cell Anemia in Pregnancy
}

\author{
Richa Saxena ${ }^{1}$, Huma Sadaf ${ }^{2}$
}

\begin{abstract}
Sickle cell disease (SCD) is the most common hereditary disease globally, linked with anemia and recurrent severe pain. Pregnancy in a patient with SCD is related with high levels of maternal and fetal morbidity and mortality. Studies on potential complications during pregnancy have generated mixed data. However, it is generally accepted that women with SCD are at higher risk of adverse pregnancy outcomes and maternal mortality. Patient care has developed much over time. Nevertheless, some of the definite management issues still remain unanswered. Excellent prenatal monitoring and aggressive intervention should be established when difficulties arise for the effective management of the pregnant patient with SCD. This article discusses the etiology and the diagnosis including the clinical presentation, investigations, neonatal screening, peripheral smear, and the available management options.

Keywords: Anemia, Eclampsia, Folic acid, Hemoglobin, Hypertension, Mortality, Preeclampsia, Sickle cell disease, Ultrasound. World Journal of Anemia (2018): 10.5005/jp-journals-10065-0038
\end{abstract}

\section{INTRODUCTION}

Sickle cell disease (SCD) is a group of genetic single-gene autosomal recessive disorders caused by the "sickle" gene, which affects hemoglobin structure. This includes sickle cell anemia (HbSS) and the heterozygous situations of hemoglobin $\mathrm{S}$ and additional clinically atypical hemoglobin, e.g., combination with hemoglobin $\mathrm{C}$ (giving $\mathrm{HbSC}$ ), combination with $\beta$-thalassemia (giving $\mathrm{HbSB}$ thalassemia), and combination with hemoglobin D, E, or O-Arab. All of these genotypes will result in a nearly comparable clinical phenotype of variable severity. Sickle cell trait ( $\mathrm{HbAS}$ ) is more common than the homozygous condition (HbSS). Sickle cell disease is most predominant in Central America, Middle East, Caribbean, and some parts of India. Therefore, this disease is typically prevalent among the immigrant population in the UK. ${ }^{1-4}$ Nwabuko et al. found out that Nigeria has high prevalence of sickle cell anemia in pregnant population. Late antenatal booking, anemia, and poor education are the major factors responsible for poor pregnancy consequences in that particular region. ${ }^{5}$

\section{Etiology}

Sickle cell disease is characterized by an abnormality in the structure of globin chain rather than its production. The most common and clinically most important form is $\mathrm{HbS}$, where there is a single amino acid substitution (from glutamic acid to valine) in the $\beta$-globin chain. This makes the hemoglobin molecule unstable in the deoxygenated state. These result in the polymerization of the abnormal hemoglobin in low-oxygen conditions, leading to the formation of rigid and fragile sickle-shaped red cells. ${ }^{6-8}$ These cells are liable to an increased breakdown, which causes hemolytic anemia, and vaso-occlusion in the small blood vessels. These are responsible for most of the complications of SCD, including acute painful crises, stroke, pulmonary hypertension $(\mathrm{PH})$, renal dysfunction, retinal disease, leg ulcers, cholelithiasis, and avascular necrosis (which ordinarily disturbs the femoral head and may require hip replacement). Kato et al. describe hemolysis as a major factor responsible for severity as well as complications of sickle cell anemia. ${ }^{9}$ Previously SCD was related to a high rate of early mortality. However, these days in the UK, majority of children born with SCD have an average life expectancy of about mid-50s. Thus, the

\author{
1Jaypee Brothers Medical Publishers, New Delhi, India \\ ${ }^{2}$ Faculty of Dentistry, Jamia Millia Islamia, New Delhi, India \\ Corresponding Author: Richa Saxena, Jaypee Brothers Medical \\ Publishers, New Delhi, India, Phone: +91 8527844200, e-mail: \\ synapse94@hotmail.com \\ How to cite this article: Saxena R, Sadaf H. Sickle Cell Anemia in \\ Pregnancy. World J Anemia 2018;2(3-4):90-95. \\ Source of support: Nil \\ Conflict of interest: None
}

women with SCD are likely to live till the reproductive age-group and conceive and become pregnant.

\section{Diagnosis}

\section{Clinical Presentation}

Clinical features of sickle cell syndrome include chronic hemolytic anemia, painful crisis, hyposplenism, increased risk of infection, avascular bone necrosis, and increased risk of cerebrovascular accident. ${ }^{10}$

A prospective cohort study done by Resende Cardoso et al. on two groups of pregnant women: group I (hemoglobin SS and three hemoglobin $S / \beta^{0}$-thalassemia) or group II (hemoglobin SC and one hemoglobin $S / \beta^{+}$-thalassemia) reveals that vaso-occlusive crisis, transfusions in antepartum and postpartum period and preterm deliveries were more frequently seen among group I. Risk of infection and episodes of painful crisis were the same among both the groups. Almost one third of women had a near miss. ${ }^{11}$

\section{INVESTIGATIONS}

According to National Health Service (NHS), UK, screening before pregnancy is necessary to assess the carrier of sickle gene or severity of sickle disease. The NHS recommends tests to be done before 10 weeks of pregnancy.

\section{Screening for PH with Echocardiography}

In patients having SCD, the occurrence of $\mathrm{PH}$ is increased and is linked with a rise in mortality rate. A review article published by Simonneau and Parent says that there is a $30 \%$ risk of developing

(c) The Author(s). 2018Open Access This article is distributed under the terms of the Creative Commons Attribution 4.0 International License (https://creativecommons. org/licenses/by-nc/4.0/), which permits unrestricted use, distribution, and non-commercial reproduction in any medium, provided you give appropriate credit to the original author(s) and the source, provide a link to the Creative Commons license, and indicate if changes were made. The Creative Commons Public Domain Dedication waiver (http://creativecommons.org/publicdomain/zero/1.0/) applies to the data made available in this article, unless otherwise stated. 
PH with SCD. ${ }^{12}$ A tricuspid regurgitant jet velocity of $>2.5 \mathrm{~m} / \mathrm{second}$ through the tricuspid valve is related with an increased risk of $\mathrm{PH} .{ }^{13}$

\section{Screening for Preeclampsia}

Measurement of blood pressure and urinalysis (for proteinuria) should be performed to identify women with preeclampsia. Renal and liver function tests should be performed annually to identify sickle nephropathy and/or deranged hepatic function. ${ }^{14}$

\section{Retinal Screening}

Proliferative retinopathy is common in patients with SCD, especially patients with $\mathrm{HbSC}$, and can lead to loss of vision.

\section{Screening for Iron Overload}

In women with a higher ferritin level, or those who have had transfusion in the past, $\mathrm{T} 2$ star cardiac magnetic resonance imaging should be executed to measure the body's iron load.

\section{Screening for Red Cell Antibodies}

Presence of red cell antibodies may indicate an increased risk of hemolytic disease of the newborn.

\section{Neonatal Disease Screening}

Pilot studies on newborn screening for SCD worldwide indicate the use of high-performance liquid chromatography or electrophoresis. ${ }^{15}$ However, nowadays many point-of-care devices are available for screening, which are either paper-based screening protocols or antibody-based rapid diagnostic devices with lateral flow immunoassay technologies. To analyze the effectiveness of new screening method, Piety et al. performed a cohort on 159 newborns, suggesting $81.8 \%$ sensitivity and $83.3 \%$ specificity for HBs, and $100.0 \%$ sensitivity and $70.7 \%$ specificity for SCD in the newborns. ${ }^{16}$

Peripheral smear in case of sickle cell anemia shows the presence of crescent-shaped target cells. There may be presence of characteristic sickle-shaped cells (Fig. 1). If the person is asplenic, there may be presence of red blood cells containing nuclear material (Howell-Jolly bodies). ${ }^{17}$

\section{Management}

A review published by Rogers and Molokie indicates that pregnant women having SCD suffer more due to the undergoing normal

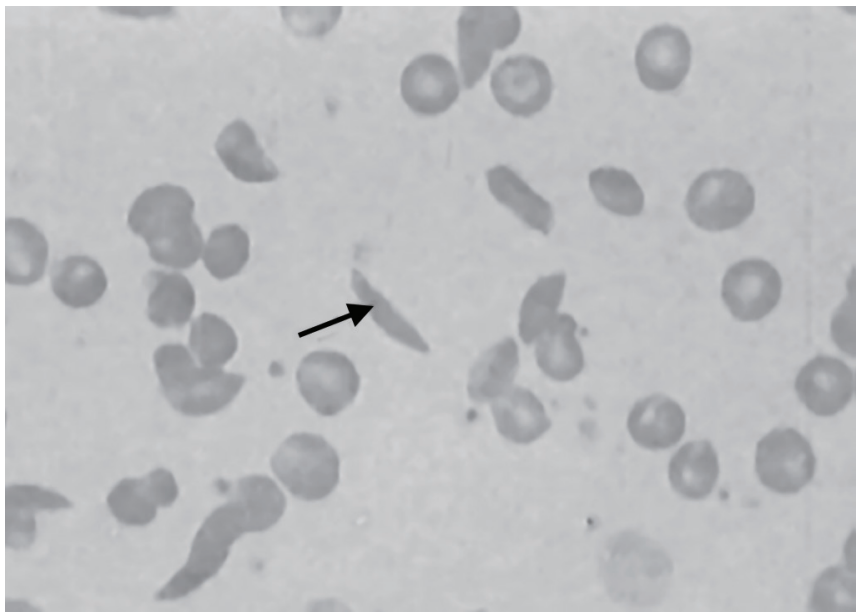

Fig. 1: Peripheral smear in case of sickle cell anemia (arrow indicates sickle-shaped cells) physiological pregnancy changes as well as the damages caused by SCD. All these changes might affect the vital organs adversely. A meticulous approach to manage the condition can save the mother as well as the fetus from debilitating complications. ${ }^{18}$

\section{Preconceptual Care}

It is usual to diagnose SCD during pregnancy because a vast majority of infected individuals are aware of the diagnosis right from the childhood. Milder forms of the disease (e.g., HbSC) may be diagnosed for the first time during pregnancy or just prior to conception.

\section{Prepregnancy Counseling}

Green-top Guidelines (2011) of Royal College of Obstetricians and Gynecologists (RCOG) suggest screening of end-organ damage in women having SCD should be seen preconceptually by a sickle specialist. ${ }^{19}$ Primary care physicians have a noteworthy role in preconceptual screening, together with the provision of contraceptive advice. Women suffering from SCD should be given not only the general preconceptual care, which is delivered to all women, but also extra instruction allied to vaccinations, medications, and circumvention of sickling crisis. She should be counseled regarding the role of dehydration, cold, hypoxia, overexertion, and stress in precipitating the sickle cell crises. She should also be advised regarding the risk of deteriorating anemia, the increased risk of sickling crises, acute chest syndrome (ACS), and the risk of increased infection (especially urinary tract infection) during pregnancy. ${ }^{20}$

\section{Genetic Screening}

Hemoglobinopathy status of the partners of the patients with SCD should be determined before they get on with their pregnancy. If a partner is identified as a carrier of, or affected by, a major hemoglobinopathy, per the National Screening Committee Guidance, they should receive counseling and advice regarding the reproductive options. For couples having in vitro fertilization, sperm donors should also be screened for hemoglobinopathies. ${ }^{21}$

\section{Supplementation with Folic Acid}

According to the World Health Organization (WHO), $60 \mathrm{mg}$ of elemental iron and $400 \mu \mathrm{g}$ of folic acid, once or twice a day, should be given to every pregnant woman. However, Green-top Guidelines (2011) of RCOG recommend $5 \mathrm{mg}$ of folic acid once in a day for a pregnant woman with SCD preconceptually as well as during gestation. A randomized controlled trial conducted by Blencowe reveals that folic acid could possibly reduce the risk of miscarriage and birth defects such as spina bifida in the fetus. ${ }^{22}$

\section{Hydroxycarbamide}

This drug has proved to reduce the occurrence of difficulties such as acute painful crises and ACS in individuals with SCD. Hydroxycarbamide (hydroxyurea) should be stopped at least 3 months before conception in lieu of its teratogenic effects. If the woman conceives while taking this drug, stopping the intake of the drug and conducting level III ultrasound is the standard management protocol which must be followed. Surgical termination of pregnancy is not recommended based on the exposure to hydroxycarbamide alone. ${ }^{23}$ However, the teratogenic effects are only seen on animal models.

A randomized double-blind placebo-controlled trial (2009) conducted to see the teratogenic effects of hydroxycarbamide 
indicates that this drug causes substantial reduction in painful crisis in the patients and it had no teratogenic effect on the preterm birth as well as full-term birth. ${ }^{24}$

\section{Angiotensin-converting Enzyme Inhibitors and Angiotensin Receptor Blockers}

A randomized or quasi-randomized controlled trial on $A C E$ inhibitors was published in Cochrane Database of Systematic Reviews (2015), indicating potential benefits of ACE inhibitors. The study demonstrates decrease in mean urinary albumin excretion due to captopril intake for 6 months by a difference of -49.00 ( $95 \%$ confidence interval: -124.10 to 26.10$){ }^{25}$

Patients having SCD are more likely to have microalbuminuria, renal dysfunction, and proteinuria. Angiotensin receptor blockers or angiotensin-converting enzyme inhibitors are more commonly used with significant proteinuria in patients with SCD (proteincreatinine ratio of more than $50 \mathrm{mg} / \mathrm{mmol}$ ). These drugs should be stopped before conception. ${ }^{26}$

\section{Antenatal Period}

\section{Multidisciplinary Team Approach}

A study conducted in Korle-Bu Teaching Hospital in Accra, Ghana, was done to assess the benefits of multidisciplinary obstetrichematology care team for women with SCD in a combined SCDobstetric clinic. The results of the study were surprising enough. A multidisciplinary team approach reduced the maternal mortality rate from 10,791 per 100,000 live births to 1,176 per 100,000 , with 89.1\% ( $p=0.007)$ decrement in risk. Perinatal mortality also reduced from 60.8 per 1,000 total births before to 23.0 per 1,000 after, with $62.2 \%(p=0.20)$ decrement in total risk. ${ }^{27}$

\section{Vaccination}

Di Nuzzo and colleagues consider vaccination as a crucial step to limit the infection to a large extent. ${ }^{28}$ They recommend influenza vaccine if it has not been administered in the previous year. Live-attenuated vaccines should be deferred until after delivery. Additionally, women should be given Haemophilus influenzae type II and the conjugated meningococcal $C$ vaccine as a single dose if they have not received it as part of the primary vaccination. The pneumococcal vaccine (Pneumovax ${ }^{\circledR}$ ) should be administered at every 5 -year interval. ${ }^{29}$ Hepatitis B vaccination is also recommended and the woman's immune status should be determined preconceptually. Women with SCD should be advised to receive the influenza and "swine flu" vaccine annually. Penicillin prophylaxis and vaccinations, which are usually observed and managed in primary care during the nonpregnant state, should be studied by an expert hematologist or obstetrician during pregnancy.

\section{Medications}

Green-top Guideline No. 61 (2011) provided by RCOG describes that if a woman has not undergone a preconceptual review, she should be counseled to take daily folic acid supplements and prophylactic antibiotics. If the prophylactic antibiotics are contraindicated, it should not be taken. Drugs that are unsafe to be used in pregnancy should be stopped and iron intake should be considered only if there is an evidence of iron deficiency. Low-dose aspirin in the dosage of $75 \mathrm{mg}$ once daily must be prescribed from 12 weeks of gestation in order to reduce the risk of preeclampsia development. Women with SCD should be advised to receive prophylactic lowmolecular-weight heparin during antenatal hospital admissions.
Nonsteroidal anti-inflammatory drugs (NSAIDs) should be prescribed only between 12 weeks and 28 weeks of gestation due to the concerns regarding adverse effects on fetal development.

\section{Monitoring for Preeclampsia}

A review published by author Ryan $\mathrm{K}$ of Central Manchester University Hospitals, the NHS Foundation Trust considers hypertension and preeclampsia to be crucial risk factors resulting in maternal morbidity with SCD. During each visit for consult, urinalysis and blood pressure should be monitored. Midstream urine for culture and sensitivity must be performed on monthly basis to rule out infection. ${ }^{30}$

\section{Ultrasound Scanning}

National Health Service (UK) recommends a pregnant woman with SCD to get tested at least every 4 weeks until 28 weeks of pregnancy followed by close monitoring through ultrasound scans every 2 weeks until 36 weeks and more frequently after that to keep a keen eye on the health of mother and baby. ${ }^{31}$

\section{Prophylactic Transfusion}

Routine prophylactic transfusion is not recommended during pregnancy for women with SCD. Top-up transfusion is indicated for women with acute anemia. ${ }^{32}$

\section{Management of Iron Overload and Folic Acid Supplementation}

Ferritin levels must be checked and if found to be elevated or if there is a previous history of iron overload, the woman must be offered the following investigations: echocardiography or cardiac assessment (to rule out cardiomyopathy) and regular assessment of renal and hepatic functions. Folic acid in the dose of $5 \mathrm{mg} / \mathrm{day}$ must be administered throughout the pregnancy. Levels of $\mathrm{Hb}$ and $\mathrm{HbS}$ must also be regularly assessed.

\section{Alloimmunization}

Alloimmunization (the formation of antibodies to red cell antigens) is common in SCD and can occur in approximately $18-36 \%$ of patients. Alloimmunization is clinically important as it can lead to delayed hemolytic transfusion reactions or hemolytic disease of the newborn and can render the patients untransfusable. The risk of alloimmunization is significantly reduced by giving red cells matched for the $\mathrm{C}, \mathrm{E}$, and Kell antigens. This should be the standard practice not only for pregnant patient but also for all patients with SCD even if they are nonpregnant.

\section{Management of Acute Painful Crisis}

The WHO considers sickle cell crisis a matter of urgency. Management options such as administering analgesia and evaluation by multidisciplinary team should be given to the pregnant women presenting with acute painful crisis. Urgent referral to hospital should be considered only in those cases when a woman has symptoms of shortness of breath, atypical pain, febrile conditions, and pain that does not settle with simple analgesic drugs. The management of pain must be done using the WHO analgesic ladder, starting with paracetamol, rest, and oral fluids for mild pain. ${ }^{19}$

Mild to moderate pain occurring from 12 weeks to 28 weeks of gestation can be managed with NSAIDs. Morphine which is a stronger opioid can be used for severe pain, while moderate pain can be managed with weak opioids. Depending 
upon the preference of the patient, morphine or diamorphine can be administered by the oral, subcutaneous, intramuscular, or intravenous (IV) route. Parenteral opiates can be given by intermittent bolus or patient-controlled administration systems. Opiates are not associated with teratogenicity or congenital malformation but may be associated with transient suppression of fetal movement and a reduced baseline variability of the fetal heart rate. Where a mother has received prolonged administration of opiates in late pregnancy, the neonate should be observed for signs of opioid withdrawal. Pethidine should be avoided in patients with SCD. Thromboprophylaxis can also be given to women with SCD who are admitted to hospital with painful crises.

\section{Fluid Intake}

Fluid intake of at least $60 \mathrm{~mL} / \mathrm{kg} / 24$ hours should be ensured. This can be administered either orally or intravenously if the woman is not able to accept adequate fluids orally.

\section{Oxygen Saturation}

While monitoring oxygen and if the oxygen saturation drops below $95 \%$, the patient should be treated immediately. O'Driscoll et al. suggest to maintain 94-98\% oxygen saturation in a patient during sickle cell crisis. ${ }^{33}$ The clinician should start intensive care therapy in initial stages itself if satisfactory oxygen saturation cannot be preserved by oxygen administration through facial or nasal route.

\section{Management of ACS}

Wright et al. say that early recognition of ACS is important. Each hospital should have a protocol in place for the management of ACS in pregnancy, including the use of transfusion therapy. The author describes respiratory symptoms such as tachypnea, chest pain, cough, and shortness of breath as characteristic symptoms of ACS. There may be the presence of a new infiltrate on the chest $X$-ray. In these cases, pneumonia and acute severe infection with the H1N1 virus must be ruled out due to an overlap in symptoms. Similar to the nonpregnant women, treatment in these cases is with IV antibiotics, oxygen, and blood transfusion. ${ }^{34}$

\section{Management of Acute Anemia}

Author Nguyen describes erythrovirus (earlier known as parvovirus) infection as a causative agent for acute anemia in women with SCD, which may cause a red cell maturation arrest and an aplastic crisis characterized by reticulocytopenia. ${ }^{35}$ Therefore, a reticulocyte count should be requested in any woman presenting with an acute anemia. Thus, women should be isolated and the management is with blood transfusion. There is an additional possibility of vertical transmission of erythrovirus infection to the fetus, which might result in hydrops fetalis. Thus, an evaluation by a fetal medicine expert is recommended. ${ }^{36}$

\section{Intrapartum Care}

Overall findings of a study conducted by Boulet et al. indicate that women with SCD are at very high risk of developing complications during delivery as compared to women with the same risk but without SCD. Therefore, women with SCD should be advised to give birth in hospitals that are able to manage both the complications of SCD and the high-risk pregnancy. The relevant multidisciplinary team (senior midwife in charge, senior obstetrician, anesthetist, and hematologist) should be informed as soon as the labor is confirmed. ${ }^{37,38}$

The study reveals almost $13 \%$ of women with SCD had transfusion during the intrapartum or postpartum period.
Any deteriorating feature should be recognized fast to avoid possible complications. Vital signs must be observed on an hourly basis. Investigations must be undertaken in case the temperature is raised over $37.5^{\circ} \mathrm{C}$. Women should be kept warm and adequate hydration (either through oral or through IV route) be maintained during labor. There is an increased demand for oxygen during the intrapartum period. Pulse oximetry must be used to detect hypoxia in the mother during labor. Arterial blood gas analysis should be performed and oxygen therapy instituted if oxygen saturation is $\leq 94 \%$.

Routine antibiotic prophylaxis in labor is presently not supported by the available evidence. ${ }^{39}$ The clinician should, however, have a low threshold to initiate broad-spectrum antibiotics. Blood should be cross matched for delivery if atypical antibodies are present because this may postpone the accessibility of blood. Or else, a "group and save" ascertains to be appropriate. It is very much significant to discuss appropriate positions for delivery in women who have hip replacements due to avascular necrosis.

Women with SCD should be presented anesthetic evaluation in the third trimester of pregnancy. Pethidine should be evaded. Nevertheless, other opiates can be utilized. Regional analgesia is suggested for cesarean delivery. Use of general anesthesia should be avoided. Pregnant women with SCD with a normally growing fetus should be offered elective birth through induction of labor or by elective cesarean section (in presence of obstetric or medical indications) after $38^{+0}$ weeks of gestation. Continuous intrapartum electronic fetal heart rate monitoring is recommended due to an increased risk of fetal distress, which may require an operative delivery.

\section{Postpartum Period}

Statistical analysis done by author Olugbenga indicates that pregestational counseling and care, social class, parity, and early antenatal booking lead to favorable outcomes with huge reduction in prematurity, preterm labor, and the mean fetal weights. However, several complications can occur during postpartum period. Meticulous care should be taken such as maternal oxygen saturation must be maintained above $94 \%$. Adequate hydration must also be maintained. Low-molecular-weight heparin should be given to the patient while in hospital and 7 days post-discharge following vaginal delivery or for a period of 6 weeks following cesarean delivery. ${ }^{40,41}$

A retrospective study was performed from 2006 to 2016 at Guy's and St. Thomas' Hospital, UK, which leads to the conclusion that the median number of postpartum admission was 7 with a varied range of 4-54. In the study, all the women were required to be admitted to a level II or higher care ward in the postnatal period. ${ }^{42}$

Since severe complications of SCD and acute crisis can develop in puerperium, the same level of care and vigilance should be sustained as has been termed for antenatal care. Progestogencontaining contraceptives such as the progesterone-only pill $\left(\right.$ Cerazette $^{\circledast}$ ), injectable contraceptives (Depo-Provera ${ }^{\circledast}$ ), and the levonorgestrel intrauterine system (Mirena ${ }^{\oplus}$ ) are safe and effective in SCD. Estrogen-containing contraceptives should be used as the second-line agents.

\section{Complications}

An observational study performed by Elenga et al. indicates pregnant females with SS phenotype are at more risk of developing SCD. The study describes anemia as the most common maternofetal 
complication (36.5\%) followed by infection (31.7\%), vaso-occlusive crisis $(20.6 \%)$, preeclampsia $(17.5 \%)$, premature birth $(11.1 \%)$, intrauterine growth retardation (15.9\%), abnormal fetal heart rate (14.3\%), and intrauterine fetal death (4.8\%). ${ }^{43}$

Maternal complications can occur during pregnancy as well including acute painful crises, spontaneous miscarriage, antenatal hospitalization, delivery by cesarean section, infection, thromboembolic events, antepartum hemorrhage, increased risk of preeclampsia, eclampsia, pregnancy-induced hypertension (PIH), peripartum cardiomyopathy, and increased maternal mortality and morbidity. ${ }^{44-46}$

Fetal complications include an increased incidence of perinatal mortality, premature babies, fetal growth restriction, and fetal distress (which may necessitate induction of labor or operative delivery). ${ }^{40}$

\section{Conclusion}

Prepregnancy counseling remains the gold standard in cases of SCD. However, if that is not possible, further screening and counseling regarding the prenatal diagnosis is required. Folic acid supplementation (in the dosage of $5 \mathrm{mg} /$ day) and penicillin prophylaxis should be continued for the duration of pregnancy. Universal antenatal and neonatal screening for the inherited hemoglobinopathies is being considered because selective screening is not effective. Neonatal screening for inherited hemoglobinopathies reduces morbidity and mortality by early diagnosis and prompt treatment.

\section{References}

1. Chakravarti A, Li CC, Buetow KH. Estimation of the marker gene frequency and linkage disequilibrium from conditional marker data. Am J Hum Genet 1984;36(1):177-186.

2. Davies SC, Brozovi M. The presentation, management and prophylaxis of sickle cell disease. Blood Rev 1989;3(1):29-44. DOI: 10.1016/0268960X(89)90023-4.

3. Serjeant $\mathrm{GR}$. The emerging understanding of sickle cell disease. $\mathrm{Br}$ J Haematol 2001;112(1):3-18. DOI: 10.1046/j.1365-2141.2001.02557.x.

4. Streetley A, Latinovic R, Hall K, et al. Implementation of universal newborn bloodspot screening for sickle cell disease and other clinically significant haemoglobinopathies in England: screening results for 2005-2007. J Clin Pathol 2009;62(1):26-30. DOI: 10.1136/ jcp.2008.058859.

5. Nwabuko OC, Okoh DA, lyalla C, et al. Prevalence of sickle cell disease in pregnancy in Nigeria. Sub-Saharan Afr J Med 2016;3(3):132-136. DOI: 10.4103/2384-5147.190843.

6. Steinberg MH. Pathophysiology of sickle cell disease. Baillieres Clin Haematol 1998;11(1):163-184. DOI: 10.1016/S0950-3536(98)80074-7.

7. Rodgers GP. Overview of pathophysiology and rationale for treatment of sickle cell anemia. Semin Hematol 1997;34(3 Suppl 3):2-7.

8. Chakravorty S, Williams TN. Sickle cell disease: a neglected chronic disease of increasing global health importance. Arch Dis Child 2015;100(1):48-53. DOI: 10.1136/archdischild-2013-303773.

9. Kato GJ, Gladwin MT, Steinberg MH. Deconstructing sickle cell disease: reappraisal of the role of hemolysis in the development of clinical subphenotypes. Blood Rev 2007;21(1):37-47. DOI: 10.1016/j. blre.2006.07.001.

10. Serjeant GR. The clinical features of sickle cell disease. Baillieres Clin Haematol 1993;6(1):93-115. DOI: 10.1016/S0950-3536(05)80067-8.

11. Resende Cardoso PS, Lopes Pessoa de Aguiar RA, Viana MB. Clinical complications in pregnant women with sickle cell disease: prospective study of factors predicting maternal death or near miss. Rev Bras Hematol Hemoter 2014;36(4):256-263. DOI: 10.1016/j.bjhh.2014.05.007.

12. Simonneau G, Parent F. Pulmonary hypertension in patients with sickle cell disease: not so frequent but so different. Eur Resp J 2012;39(1):3-4. DOI: 10.1183/09031936.00119811.
13. Willen SM, Gladwin MT. What is the role of screening for pulmonary hypertension in adults and children with sickle cell disease? Hematol Am Soc Hematol Educ Program 2017;2017(1):431-434. DOI: 10.1182/ asheducation-2017.1.431.

14. Uzan J, Carbonnel M, Piconne O, et al.Pre-eclampsia: pathophysiology, diagnosis, and management. Vasc Health Risk Manag 2011;7:467-474. DOI: 10.2147/VHRM.S20181.

15. El-Haj N, Hoppe CC. Newborn screening for SCD in the USA and Canada. Int J Neonatal Screen 2018;4(4):36. DOI: 10.3390/ijns4040036.

16. Piety NZ, George A, Serrano S, et al. A paper-based test for screening newborns for sickle cell disease. Sci Rep 2017;7:45488. DOI: 10.1038/ srep45488.

17. Ilesanmi OO. Pathological basis of symptoms and crises in sickle cell disorder: implications for counseling and psychotherapy. Hematol Rep 2010;2(1):e2. DOI: 10.4081/hr.2010.e2.

18. Rogers DT, Molokie R. Sickle cell disease in pregnancy. Obstet Gynecol Clin North Am 2010;37(2):223-237. DOI: 10.1016/j.ogc.2010.02.015.

19. RCOG. (2011). Green top Guidelines no. 61. Management of Sickle Cell Disease in Pregnancy. [online] Available from https://www.rcog.org. uk/globalassets/documents/guidelines/gtg_61.pdf, last accessed December, 2019.

20. Brousse V, Makani J, Rees DC. Management of sickle cell disease in the community. BMJ 2014;348:g1765. DOI: 10.1136/bmj.g1765.

21. Ghosh K, Colah R, Manglani M, et al. Guidelines for screening, diagnosis and management of hemoglobinopathies. Indian J Hum Genet 2014;20(2):101-119. DOI: 10.4103/0971-6866.142841.

22. Blencowe $\mathrm{H}$, Cousens $\mathrm{S}$, Modell B, et al. Folic acid to reduce neonatal mortality from neural tube disorders. Int J Epidemiol 2010;39(1):i 110-i121. DOI: 10.1093/ije/dyq028.

23. Russell EW. Hydroxycarbamide: clinical aspects. C R Biol 2013;336(3):177-182. DOI: 10.1016/j.crvi.2012.09.006.

24. Ballas SK, McCarthy WF, Guo N, et al. Exposure to hydroxyurea and pregnancy outcomes in patients with sickle cell anemia. J Natl Med Assoc 2009;101(10):1046-1051. DOI: 10.1016/S0027-9684(15)31072-5.

25. Sasongko TH, Nagalla S, Ballas SK. Angiotensin-converting enzyme (ACE) inhibitors for proteinuria and microalbuminuria in people with sickle cell disease. Cochrane Database Syst Rev 2015;6:CD009191. DOI: 10.1002/14651858.CD009191.pub3.

26. Ajmal A, Gessert CE, Johnson BP, et al. Effect of angiotensin converting enzyme inhibitors and angiotensin receptor blockers on hemoglobin levels. BMC Res Notes 2013;6:443. DOI: 10.1186/1756-0500-6-443.

27. Asare EV, Olayemi E, Boafor T, et al. Implementation of multidisciplinary care reduces maternal mortality in women with sickle cell disease living in low-resource setting. Am J Hematol 2017;92(9):872-878. DOI: 10.1002/ajh.24790.

28. Di Nuzzo DV, Fonseca SF. Sickle cell disease and infection. J Pediatr (Rio J) 2004;80(5):347-354. DOI: 10.2223/1218.

29. Mehta SR, Afenyi-Annan A, Byrns PJ, et al. Opportunities to improve outcomes in sickle cell disease. Am Fam Physician 2006;74(2):303-310.

30. Ryan K. NHS Foundation Trust. 2019. Sickle cell disease and pregnancy. [online] Available from https://www.transfusionguidelines.org, last accessed December, 2019.

31. NHS. Sickle Cell and Thallassaemia Centre. Pregnancy advice for women with Sickle Cell Disease. [online] Available from http://www. swbh.nhs.uk/wp-content/uploads/2012/07/Pregnancy-advicefor-women-with-sickle-cell-disease-ML3704.pdf, last accessed December, 2019.

32. Malinowski AK, Shehata N, D'Souza R, et al. Prophylactic transfusion for pregnant women with sickle cell disease: a systematic review and meta-analysis. Blood 2015;126(21):2424-2435. DOI: 10.1182/blood2015-06-649319.

33. O'Driscoll BR, Howard LS, Davison AG, et al. BTS guideline for emergency oxygen use in adult patients. Thorax 2008;63(Suppl 6):vi1-vi68. DOI: 10.1136/thx.2008.102947.

34. Wright $D$, Kenny-Scherber $C$, Montgomery A, et al. Acute coronary syndrome in pregnancy. Clin Med Cardiol 2009;3:125-131. DOI: 10.4137/CMC.S3284. 
35. Nguyen QT, Sifer C, Schneider V, et al. Novel human erythrovirus associated with transient aplastic anemia. J Clin Microbiol 1999;37(8):2483-2487. DOI: 10.1128/JCM.37.8.2483-2487.1999.

36. Amel EA, Mangaiarkkarasi A. Evaluation of anaemia in booked antenatal mothers during the last trimester. J Clin Diagn Res 2013;7(11):2487-2490. DOI: 10.7860/JCDR/2013/6370.3586.

37. Gaston $M H$, Verter JI, Woods G, et al. Prophylaxis with oral penicillin in children with sickle cell anaemia. A randomized trial. N Engl J Med 1986;314(25):1593-1599. DOI: 10.1056/ NEJM198606193142501.

38. Boulet SL, Okoroh EM, Azonobi l, et al. Sickle cell disease in pregnancy: maternal complications in a medicaid-enrolled population. Matern Child Health J 2013;17(2):200-207. DOI: 10.1007/ s10995-012-1216-3.

39. Working Party of the British Committee for Standards in Haematology Clinical Haematology Task Force. Guidelines for the prevention and treatment of infection in patients with an absent or dysfunctional spleen. BMJ 1996;312(7028):430-434. DOI: 10.1136/ bmj.312.7028.430.
40. Milman N. Postpartum anemia II: prevention and treatment. Ann Hematol 2012;91(2):143-154. DOI: 10.1007/s00277-011-1381-2.

41. Olugbenga AO. Managing sickle cell disease in pregnancy, the success and the challenges: our experience in a semi-urban tertiary health-care facility, Southwest, Nigeria. Trop J Obstetr Gynaecol 2018;35(3):342-347. DOI: 10.4103/TJOG.TJOG_37_18.

42. Cardosa D, Ridout A, Nanda S, et al. Maternal sickle cell disease and twin pregnancy: a case series and review of the literature. Hematology 2019;24(1):148-158. DOI: 10.1080/10245332.2018.1535534.

43. Elenga N, Adeline A, Balcaen J, et al. Pregnancy in sickle cell disease is a very high-risk situation: an observational study. Obstet Gynecol Int 2016;2016:9069054. DOI: 10.1155/2016/9069054.

44. Jain D, Atmapoojya P, Colah R, et al. Sickle cell disease and pregnancy. Mediterr J Hematol Infect Dis 2019;11(1):e2019040. DOI: 10.4084/ mjhid.2019.040.

45. Sifakis S, Pharmakides G. Anemia in pregnancy. Ann N Y Acad Sci 2000;900:125-136. DOI: 10.1111/j.1749-6632.2000.tb06223.x.

46. Akhter S, Momen MA, Rahman MM, et al. Effect of maternal anemia on fetal outcome. Mymensingh Med J 2010;19(3):391-398. 